\title{
Relationship Between the Presence of Eczema Herpeticum and the Significance of Clinical and Laboratory Tests in Korean Children With Atopic Dermatitis
}

\author{
Kohwoon Kim, ${ }^{1}$ Junseok Kang, ${ }^{1}$ Sung Won Kim, ${ }^{1}$ and Myongsoon Sung ${ }^{2,}{ }^{*}$ \\ ${ }^{1}$ Department of Pediatrics, Busan St. Mary's Hospital, Busan, Korea \\ ${ }^{2}$ Department of Pediatrics, CHA Gumi Medical Center, CHA University School of Medicine, Gumi, Korea \\ "Corresponding author: Myongsoon Sung, Department of Pediatrics, CHA Gumi Medical Center, CHA University School of Medicine, Gumi, Korea. Tel: +82-544509700, Fax: \\ +82-544509970, E-mail: myong47@hanmail.net
}

Received 2015 November 11; Revised 2016 February 17; Accepted 2016 March 09.

\begin{abstract}
Background: Eczema herpeticum (EH) is a herpes simplex virus (HSV) infection superimposed on atopic dermatitis (AD). Objectives: The aim of this study was to evaluate the relationship between clinical features and laboratory tests, including skin cultures, total IgE, eosinophil count, eosinophil cationic protein, and 25-hydroxyvitamin $\mathrm{D}_{3}(25-(\mathrm{OH}) \mathrm{D} 3)$, in Korean children with AD according to the presence of EH.

Patients and Methods: We enrolled 380 patients aged 6 months to 18 years who were admitted to Busan St. Mary's hospital from January 2012 to December 2014 . All 380 subjects were divided into two groups: the control and the AD group. The AD group was further divided into two subgroups: $\mathrm{EH}^{+}$and $\mathrm{EH}^{-}$.

Results: The male gender was related to the presence of $\mathrm{EH}$ (odds ratio of 2.56 ; $95 \%$ confidence interval, $1.19-5.53, \mathrm{P}=0.01)$, but age and $25-(\mathrm{OH}) \mathrm{D}_{3}$ levels were not. After adjusting for age, gender, and $25-(\mathrm{OH}) \mathrm{D}_{3}$, no significant relationship was found between total IgE, eosinophil cationic protein or eosinophil count levels and the presence of EH. The relationship between positive skin cultures and the presence of EH was significant $(\mathrm{P}<0.001)$ and the presence of methicillin-resistant Staphylococcus aureus (MRSA) was also related to the development of $\mathrm{EH}(\mathrm{OR}, 0.19 ; 95 \% \mathrm{CI}, 0.04-0.92, \mathrm{P}=0.03)$.

Conclusions: We conclude that while male gender, positive skin culture results, and the presence of MRSA are factors influencing EH, serum $25-(\mathrm{OH}) \mathrm{D}_{3}$ levels are not associated with EH in Korean AD children.
\end{abstract}

Keywords: Atopic Dermatitis, Eczema Herpeticum, Serum $25-(\mathrm{OH}) \mathrm{D}_{3}$

\section{Background}

Atopic dermatitis (AD) is a most common chronic inflammatory skin disease causing intense irritation and pruritus in children $(1,2)$. The number of $\mathrm{AD}$ patients seems to be on the rise in many developing countries, affecting over $10 \%$ of the population, while approximately $20 \%$ of people in developed countries are affected with AD (3-5).

Many complications from recurrent bacterial and viral skin infections accompany AD (6), including eczema herpeticum (EH) which is a herpes simplex virus (HSV) infection superimposed on $\mathrm{AD}$. The incidence of $\mathrm{EH}$ is as low as between $3 \%$ and $6 \%$ in patients with $\operatorname{AD}(7,8)$. $\mathrm{EH}$ usually presents as a disseminated eruption of dome-shaped monomorphic vesicles that contain multinucleated giant cells infected with HSV. It can be associated with significant systemic complications, such as keratoconjunctivitis, as well as multi-organ involvement like meningitis and encephalitis (9). The risk of advancing EH is known to be highest in children younger than 3 years of age, with an even male-to-female ratio. According to the data, this seemingly rare disease has recently increased in the population (10). $\mathrm{EH}$ is a potentially fatal condition, so patients with EH require immediate and effective antiviral therapy (11). However, even though it is a serious and increasingly prevalent disease, only a few studies have investigated a large number of patients with EH. Research on the relationship between clinical features and laboratory tests including 25hydroxyvitamin $\mathrm{D} 3\left(25-(\mathrm{OH}) \mathrm{D}_{3}\right)$ levels in $\mathrm{AD}$ children with and without $\mathrm{EH}$ are rare $(12,13)$.

\section{Objectives}

The aim of this study was to evaluate the relationship between clinical features and laboratory tests, including skin cultures, total IgE, eosinophil count, eosinophil cationic protein, and $25-(\mathrm{OH}) \mathrm{D}_{3}$ in Korean children with $\mathrm{AD}$ according to the presence of $\mathrm{EH}$.

\section{Patients and Methods}

\subsection{Participants}

This study was carried out on 380 patients aged 6 months to 18 years who were admitted to the pediatric department of Busan St. Mary hospital, Busan, Korea, between January 2012 and December 2014. The retrospective data collected from their individual medical records included demographic characteristics, historical features, and clinical features (fever, systemic symptoms, eye involvement, and type of eruption). In this study, fever was 
defined as a temperature $\geq 38^{\circ} \mathrm{C}$ and systemic symptoms included headache, anorexia, or lethargy. Eye involvement was defined as keratoconjunctivitis diagnosed by an ophthalmologist. All participants with a history of taking any vitamin D or calcium supplements or drugs that could influence the serum $25-(\mathrm{OH}) \mathrm{D}_{3}$ level, such as glucocorticoids and anti-epileptic drugs, and those who had chronic diseases or received phototherapy within the past 6 months were excluded.

The control group was composed of 130 patients with no history of allergic diseases such as allergic rhinitis, bronchial asthma, and urticaria. The AD group included 250 children who were diagnosed with AD by an allergy specialist at Busan St. Mary hospital according to the diagnostic criteria proposed by Hanifin and Rajka (14). Using the scoring atopic dermatitis (SCORAD) index, AD subject was classified as mild $(<15)$, moderate $(15-9.9)$, or severe $(\geq 40)(15)$.

The diagnosis of EH was made clinically by the same allergy specialist or dermatologist at the clinic. EH was also diagnosed by polymerase chain reaction for viral DNA obtained from blister fluid. Additionally, electron microscopy and immunofluorescence testing were used to identify HSV-infected cells. Depending on the presence of $\mathrm{EH}$ and including the patient's history, the AD group was divided into two subgroups: $\mathrm{EH}^{+}$and $\mathrm{EH}^{-}$.

\subsection{Laboratory Tests}

During the examination, blood samples were collected and centrifuged at admission. Serum $25-(\mathrm{OH}) \mathrm{D}_{3}$ level was assayed using an enzyme immunoassay kit (immunodiagnostic systems, COBAS 6000 Roche, Mannheim, Germany). For a descriptive analysis, we categorized the serum 25$(\mathrm{OH}) \mathrm{D}_{3}$ levels into three classes: deficient $(<20 \mathrm{ng} / \mathrm{mL})$, insufficient (20 - $29.9 \mathrm{ng} / \mathrm{mL})$, or sufficient ( $\geq 30 \mathrm{ng} / \mathrm{mL}$ ) (16).

Levels of eosinophil cationic protein (ECP), total IgE, and specific $\operatorname{IgE}(\mathrm{s} \operatorname{IgE}$ ) for allergens were measured using Immuno CAP 250 (Thermo Fisher Scientific, Uppsala, Sweden). A total eosinophil count was measured with an automated hematology analyzer (coulter counter STKS; Beckman Coulter, Fullerton, CA, USA) using blood samples collected in EDTA tubes.

Before treatment, a skin swab test was performed on inflamed, pus-filled, or oozing areas. One swab was collected per patient and transported to the laboratory. Swabs were inoculated directly onto blood agar plates and incubated at $35^{\circ} \mathrm{C}$ for 24 hours before being examined. If there were specific yellow colonies, a test of catalase and coagulase using the VITEK 2 (bioMerieux Inc., Durham, NC, USA) was conducted to classify the Staphylococcus aureus. If the minimal inhibitory concentration of oxacillin, determined according to the national committee for clinical laboratory standards, was $\geq 4 \mu \mathrm{g} / \mathrm{mL}$, the colonies were classified as methicillin-resistant S. aureus (MRSA).

\subsection{Ethical Considerations}

The study was approved by the institutional review board at the Busan St. Mary hospital in Busan, South Korea (BSM2014-19).

\subsection{Statistical Analysis}

All statistical analyses were performed using IBM SPSS Statistics 21.0 (IBM Co., Armonk, NY, USA). The experimental results are presented as an arithmetic mean \pm standard deviation. In the risk factor analysis, adjusted odds ratios (aORs) and 95\% confidence intervals (CIs) were obtained using multiple logistic regression analysis. Values of $\mathrm{P}<$ 0.05 were considered statistically significant.

\section{Results}

A total of 380 children participated: 130 in the control group and 250 in the $\mathrm{AD}$ group. In the control and $\mathrm{AD}$ groups, the mean age was $4.7 \pm 4.4$ years and $5.3 \pm 4.7$ years, respectively, with a female predominance. In the $\mathrm{EH}^{+}$and EH- groups, the mean age was $4.2 \pm 4.3$ years and $5.6 \pm 4.7$ years, respectively, and the $\mathrm{EH}^{+}$group showed a male predominance (Table 1$)$.

The mean 25- $(\mathrm{OH}) \mathrm{D}_{3}$ levels and the distribution of vitamin D status in each group are shown in Table 1 . There were significant differences in mean $25-(\mathrm{OH}) \mathrm{D}_{3}$ levels and the distribution of vitamin $\mathrm{D}$ status between the control and $\mathrm{AD}$ groups. There were no significant differences in mean $25-(\mathrm{OH}) \mathrm{D}_{3}$ levels between the $\mathrm{EH}^{+}$and $\mathrm{EH}^{-}$groups. There were significant differences in the distribution of vitamin D status between the $\mathrm{EH}^{+}$and $\mathrm{EH}^{-}$group. However, there is a seasonal variation in the sampling of $25-(\mathrm{OH}) \mathrm{D}_{3}$ in each group.

There was a statistically significant difference between the $\mathrm{EH}^{+}$and $\mathrm{EH}^{-}$groups with respect to parental allergic disease history but no statistically significant difference with respect to delivery method, age of AD occurrence, or duration of $\mathrm{AD}$. The difference in the mean SCORAD index severity of $\mathrm{AD}$ between the $\mathrm{EH}^{+}$and $\mathrm{EH}^{-}$groups was statistically significant. The distribution of clinical symptoms and the method of antiviral agent administration in the $\mathrm{EH}^{+}$group is shown in Table 2 .

There were significant differences in total protein and albumin between the $\mathrm{EH}^{+}$and $\mathrm{EH}^{-}$groups. Serum IgA, IgG, $\operatorname{IgM}$, and total eosinophil count levels were higher in the $\mathrm{EH}^{-}$group than in the $\mathrm{EH}^{+}$group but the differences were not statistically significant. Serum total IgE and ECP levels were higher in the $\mathrm{EH}^{+}$group than in the $\mathrm{EH}^{-}$group but the 
Table 1. Comparison of Subject Characteristics ${ }^{\mathrm{a}}$

\begin{tabular}{|c|c|c|c|c|c|c|}
\hline & \multirow[t]{2}{*}{ Control $(n=130)$} & \multicolumn{4}{|c|}{ Atopic Dermatitis } & \multirow[t]{2}{*}{ P Value $^{\mathrm{b}}$} \\
\hline & & $\mathrm{EH}^{+}, \mathbf{n}=\mathbf{5 0}$ & $E H, n=200$ & Total, $\mathbf{n}=\mathbf{2 5 0}$ & P Value $^{c}$ & \\
\hline Male & $47(36.2)$ & $30(60.0)$ & $38(19.0)$ & $68(27.2)$ & $<0.001$ & 0.07 \\
\hline Mean age, $y$ & $4.7 \pm 4.4$ & $4.2 \pm 4.3$ & $5.6 \pm 4.7$ & $5.3 \pm 4.7$ & 0.06 & 0.22 \\
\hline 25-hydroxyvitamin $D_{3}, \mathrm{ng} / \mathrm{mL}$, mean $\pm \mathrm{SD}$ & $28.1 \pm 11.5$ & $25.2 \pm 11.8$ & $22.9 \pm 10.4$ & $25.0 \pm 11.2$ & 0.17 & $<0.001$ \\
\hline Vitamin D status & & & & & 0.04 & $<0.001$ \\
\hline Sufficient, $\geq 30$ & $62(47.7)$ & $20(40.0)$ & $45(22.5)$ & $65(26.0)$ & & \\
\hline Insufficient, 20 - 29.9 & $33(25.4)$ & $14(28.0)$ & $69(34.5)$ & $83(33.2)$ & & \\
\hline Deficient, $<20$ ) & $35(26.9)$ & $16(32.0)$ & $86(43.0)$ & $102(40.8)$ & & \\
\hline Sampling season $^{\mathrm{d}}$ & & & & & $<0.001$ & $<0.001$ \\
\hline Spring & $17(13.1)$ & $12(24.0)$ & $61(30.5)$ & $73(29.2)$ & & \\
\hline Summer & $42(32.3)$ & $25(50.0)$ & $49(24.5)$ & $74(29.6)$ & & \\
\hline Autumn & $36(27.7)$ & $8(16.0)$ & $47(23.5)$ & $55(22.0)$ & & \\
\hline Winter & $35(26.9)$ & $5(10.0)$ & $43(21.5)$ & $48(19.2)$ & & \\
\hline
\end{tabular}

Abbreviation: EH, eczema herpeticum.

${ }^{\mathrm{a}}$ Values are presented as No. (\%) or mean \pm SD.

${ }^{b}$ Control group compared with atopic dermatitis group

${ }^{c} \mathrm{EH}^{+}$compared with $\mathrm{EH}^{-}$

${ }^{\mathrm{d}}$ Spring, March - May; Summer, June - August; Autumn, September - November; Winter, December - February

differences were not statistically significant. Concerning skin cultures, there was a statistically significant difference between the two groups as $S$. aureus positive results were higher in the $\mathrm{EH}^{+}$group (Table 3).

Male gender was related to the presence of $\mathrm{EH}(\mathrm{OR}, 2.56$; 95\% $\mathrm{CI}, 1.19-5.53, \mathrm{P}=0.01)$, but age and $25-(\mathrm{OH}) \mathrm{D}_{3}$ levels were not related. The relationship between serum total IgE, ECP, and total eosinophil count levels and the presence of $\mathrm{EH}$ was not significant, after adjusting for age, gender, and 25$(\mathrm{OH}) \mathrm{D}_{3}$ levels. However, the relationship between positive skin cultures and the presence of $\mathrm{EH}$ was significant after adjusting for age, gender, and $25-(\mathrm{OH}) \mathrm{D}_{3}$ levels. Regarding skin cultures, after adjusting for age, gender, and 25$(\mathrm{OH}) \mathrm{D}_{3}$ levels, the presence of MRSA was related to the presence of EH (Table 4).

\section{Discussion}

In this study, although there was a seasonal variation in $25-(\mathrm{OH}) \mathrm{D}_{3}$ level sampling, we demonstrated a high prevalence of vitamin D insufficiency and deficiency in the $\mathrm{AD}$ group when compared with the control. Vitamin D plays a major role in innate and adaptive immunity (17, 18). In innate immunity, vitamin $D$ deficiency causes disturbed function of cathelicidin, which may contribute to the pathogenesis of skin disease and cause $\mathrm{AD}(19)$. In adaptive immunity, vitamin D deficiency stimulates the induc- tion of $\mathrm{T}$ regulatory cells and contributes to the development of allergic diseases $(19,20)$. Because of these mechanisms, many studies have been conducted to understand the inverse correlation between the severity of $\mathrm{AD}$ and 25$(\mathrm{OH}) \mathrm{D}_{3}$ levels $(21,22)$. There is some assumption that the presence of $\mathrm{EH}$ may be correlated with $25-(\mathrm{OH}) \mathrm{D}_{3}$, but there has been little research on the correlation between $\mathrm{EH}$ and $25-(\mathrm{OH}) \mathrm{D}_{3}$. Recently, an EH girl whose $25-(\mathrm{OH}) \mathrm{D}_{3}$ level was $19 \mathrm{ng} / \mathrm{mL}$ and two children with widespread $\mathrm{EH}$ and low serum $25-(\mathrm{OH}) \mathrm{D}_{3}$ levels are reported $(21,23)$. In the present study, the $\mathrm{EH}^{+}$and $\mathrm{EH}^{-}$groups showed similar average 25$(\mathrm{OH}) \mathrm{D}_{3}$ levels, and serum $25-(\mathrm{OH}) \mathrm{D}_{3}$ levels were also not related to the presence of $\mathrm{EH}$. However, the distribution of vitamin D status significantly differed between these two groups. Therefore, more studies about the relationship between serum $25-(\mathrm{OH}) \mathrm{D}_{3}$ levels and the presence of EH that consider influencing factors such as sun exposure time, daily consumption of vitamin D-fortified food, and the use of sun creams are needed.

The risk factor for advancing EH is an age younger than 3 years; boys and girls are equally at risk (10). In this study, the average age, which was over 3 years, was similar between the two groups. However, boys are predominant in the $\mathrm{EH}^{+}$group and there is a significant correlation between the male gender and an increasing rate of $\mathrm{EH}$. This finding is similar to the results of a previous study. Furthermore, $\mathrm{EH}^{+}$patients have been reported to have an earlier 
Table 2. Comparison of the Clinical Characteristics of AD Children According to the Presence of $\mathrm{EH}^{\mathrm{a}}$

\begin{tabular}{|c|c|c|c|}
\hline Variables & $\mathbf{E H}^{+}(\mathbf{n}=\mathbf{5 0})$ & $\mathrm{EH}^{-}(\mathbf{n}=\mathbf{2 0 0})$ & PValue \\
\hline Vaginal delivery & $32(64.0)$ & $30(60.0)$ & 0.43 \\
\hline Parental allergy & $25(50.0)$ & $131(65.5)$ & 0.02 \\
\hline Allergic rhinitis & $22(44.0)$ & $95(47.5)$ & \\
\hline Contact dermatitis & $4(8.0)$ & $66(33.0)$ & \\
\hline $\mathrm{AD}$ & $3(6.0)$ & $5(2.5)$ & \\
\hline Bronchial asthma & $0(0.0)$ & $3(1.5)$ & \\
\hline Age of AD onset, $y$ & $1.7 \pm 2.4$ & $2.4 \pm 2.9$ & 0.09 \\
\hline AD duration, $y$ & & & 0.59 \\
\hline$<1$ & $20(40.0)$ & $71(35.5)$ & \\
\hline $1-2$ & $13(26.0)$ & $45(22.5)$ & \\
\hline$>2$ & $17(34.0)$ & $84(42.0)$ & \\
\hline SCORAD index & $47.6 \pm 17.7$ & $33.6 \pm 18.7$ & $<0.001$ \\
\hline Severity & & & $<0.001$ \\
\hline Mild & $0(0.0)$ & $37(18.5)$ & \\
\hline Moderate & $16(32.0)$ & $103(51.5)$ & \\
\hline Severe & $34(68.0)$ & $60(30.0)$ & \\
\hline Clinical symptoms & $37(74.0)$ & & \\
\hline Fever & $12(24.0)$ & & \\
\hline Systemic symptoms & $13(26.0)$ & & \\
\hline Keratoconjunctivitis & $12(24.0)$ & & \\
\hline Acyclovir treatment & $50(100)$ & & \\
\hline Intravenous & $21(42.0)$ & & \\
\hline Perioral & $29(58.0)$ & & \\
\hline Readmission & $4(8.0)$ & & \\
\hline
\end{tabular}

Abbreviations: AD, atopic dermatitis; EH, eczema herpeticum; SCORAD, SCORing atopic dermatitis.

${ }^{a}$ Values are presented as No. (\%) or mean \pm SD.

onset of skin disease than $\mathrm{EH}^{-}$patients $(24,25)$. However, in the current study, the $\mathrm{EH}^{+}$and $\mathrm{EH}^{-}$subjects showed a similar age of onset of their underlying $\mathrm{AD}$ as well as their $\mathrm{AD}$ duration. $\mathrm{EH}^{+}$subjects have been reported to have more severe $A D$, similar to the results in the present study (24). The average SCORAD index of the $\mathrm{EH}^{+}$group was significantly higher and the severity of AD was significantly worse in the $\mathrm{EH}^{+}$group than in the $\mathrm{EH}^{-}$group.

AD patients with EH frequently contract secondary bacterial skin infections. Consequently, $\mathrm{EH}^{+}$subjects reported a history of cutaneous infections with $S$. aureus infections more frequently than $\mathrm{EH}^{-}$subjects. This result suggested that staphylococcal toxins increased viral replication in skin cells and that the presence of $S$. aureus colonization or infection may increase the propensity of contracting viral skin infections (26). In the current study, the development of EH was significantly associated with MRSA, after adjusting for age, gender, and $25-(\mathrm{OH}) \mathrm{D}_{3}$ levels, and these results are similar to those of a previous study (27). Therefore, children with AD should keep their bodies clean by bathing daily with soap or cleanser to prevent a MRSA infection which may cause the development of EH. The relationship between MRSA and the presence of EH requires more research, similar to studies of the correlation between MRSA and the severity of $\operatorname{AD}(28,29)$.

High total serum IgE levels and circulating total eosinophil counts are risk factors for the development of $\mathrm{EH}$ and lead to a higher level of $\mathrm{Th}_{2}$ polarity in their immune response $(24,30,31)$. However, the current study, even after adjusting for age, gender, and $25-(\mathrm{OH}) \mathrm{D}_{3}$ levels, the serum total IgE, ECP levels, and total eosinophil count showed no increasing trend with advancing $\mathrm{EH}$. 
Table 3. Comparison of the Laboratory Test Results of AD Children According to the Presence or Absence of $\mathrm{EH}^{\mathrm{a}}$

\begin{tabular}{|c|c|c|c|}
\hline Variables & $\mathbf{E H}^{+}(\mathbf{n}=\mathbf{5 0})$ & $\mathbf{E H}(\mathbf{n}=200)$ & PValue \\
\hline Total protein, $\mathbf{g} / \mathbf{d L}$ & $6.8 \pm 0.5$ & $7.0 \pm 0.5$ & $<0.001$ \\
\hline Albumin, $\mathbf{g} / \mathbf{d L}$ & $4.3 \pm 0.3$ & $4.5 \pm 0.3$ & $<0.001$ \\
\hline IgA, IU/mL & $82.6 \pm 69.2$ & $96.2 \pm 61.6$ & 0.18 \\
\hline IgG, IU/mL & $787.9 \pm 237.7$ & $846.9 \pm 252.0$ & 0.14 \\
\hline IgM, IU/mL & $100.7 \pm 43.7$ & $113.5 \pm 44.5$ & 0.07 \\
\hline Total IgE, IU/mL & $612.1 \pm 986.0$ & $521.4 \pm 875.3$ & 0.52 \\
\hline $\mathbf{E C P}, \mu \mathbf{g} / \mathbf{L}$ & $16.5 \pm 18.7$ & $14.9 \pm 17.6$ & 0.58 \\
\hline Total eosinophil count, $\mid \mu \mathbf{L}$ & $488.6 \pm 435.7$ & $494.2 \pm 465.7$ & 0.94 \\
\hline Positive skin culture & & & $<0.001$ \\
\hline Staphylococcus aureus & $34(68.0)$ & $87(43.5)$ & \\
\hline MRSA & $15(30.0)$ & $23(11.5)$ & \\
\hline MSSA & $19(38.0)$ & $64(32.0)$ & \\
\hline Coagulase Negative Staphylococcus & $11(22.0)$ & $95(47.5)$ & \\
\hline \multicolumn{4}{|c|}{$\begin{array}{l}\text { Abbreviations: EH, eczema herpeticum, Total IgE, immunoglobulin E; ECP, eosinophil cationic protein; MRSA, methicillin-resistant Staphylococcus aureus, MSS } \\
\text { methicillin-sensitive Staphylococcus aureus. } \\
\text { a Values are presented as No. (\%) or mean } \pm \text { SD. }\end{array}$} \\
\hline
\end{tabular}

Table 4. Correlation Between the Risk Factors and Presence of $\mathrm{EH}^{\mathrm{a}}$

\begin{tabular}{|c|c|c|}
\hline Factor & OR $(95 \% \mathrm{CI})$ & PValue \\
\hline Mean age, $y$ & $1.13(0.98-1.30)$ & 0.08 \\
\hline Male gender & $2.56(1.19-5.53)$ & 0.01 \\
\hline 25-Hydroxyvitamin $D_{3}, \mathrm{ng} / \mathrm{mL}$ & $0.90(0.96-1.03)$ & 0.90 \\
\hline Total IgE, IU/mL & $1.00(0.99-1.00) c$ & $0.41 \mathrm{c}$ \\
\hline Total eosinophil count, $\mid \mu \mathbf{L}$ & $1.00(1.00-1.01) \mathrm{c}$ & $0.34 \mathrm{c}$ \\
\hline Positive skin culture & & $<0.001 \mathrm{c}$ \\
\hline MRSA & $0.19(0.04-0.92) c$ & $0.03 \mathrm{c}$ \\
\hline MSSA & $0.42(0.09-1.89) c$ & $0.26 \mathrm{c}$ \\
\hline CNS & $1.54(0.35-6.76) c$ & $0.56 \mathrm{c}$ \\
\hline
\end{tabular}

Abbreviations: CNS, coagulase-negative Staphylococcus; ECP, eosinophil cationic protein; IgE, immunoglobulin E; MRSA, methicillin-resistant Staphylococcus aureus, MSSA, methicillin-sensitive Staphylococcus aureus.

${ }^{\mathrm{a}}$ Values are presented as No. (\%) or mean \pm SD.

Several limitations are present in the current study. Firstly, owing to its retrospective nature, the diagnosis of $\mathrm{EH}$ was done at the discretion of the same allergy specialist or dermatologist in a standardized manner over the course of three years. Secondly, data on recurrence and repeated episodes may have been lost if the patient moved to another hospital. In addition, we only included patients who underwent laboratory tests that included $25-(\mathrm{OH}) \mathrm{D}_{3}$ levels. AD subjects who had no symptoms (itching, oozing, or inflammation) and had not undergone all of these tests were not included in this research. However, this study has identified certain characteristics of AD children with $\mathrm{EH}$, including its features and laboratory tests with $25-(\mathrm{OH}) \mathrm{D}_{3}$ and skin cultures.

Therefore, we conclude that male gender, positive skin culture results, and the presence of MRSA are factors influencing $\mathrm{EH}$, but that serum $25-(\mathrm{OH}) \mathrm{D}_{3}$ levels are not associated with $\mathrm{EH}$ in Korean $\mathrm{AD}$ children. 


\section{Footnote}

Authors' Contribution: Kohwoon Kim: concept, drafting of the manuscript, critical revision of the manuscript. Myongsoon Sung: concept, design, critical revision of the manuscript. Junseok Kang: concept, design, acquisition of data, DATA analysis. Sung Won Kim: acquisition of data, data analysis. All authors approved the final version of the article.

\section{References}

1. Lee SI, Kim J, Han Y, Ahn K. A proposal: Atopic Dermatitis Organizer (ADO) guideline for children. Asia Pac Allergy. 2011;1(2):53-63. doi: 10.5415/apallergy.2011.1.2.53. [PubMed: 22053298].

2. Schneider L, Tilles S, Lio P, Boguniewicz M, Beck L, LeBovidge J, et al. Atopic dermatitis: a practice parameter update 2012. J Allergy Clin Immunol. 2013;131(2):295-9. doi: 10.1016/j.jaci.2012.12.672. [PubMed: 23374261].

3. Shaw TE, Currie GP, Koudelka CW, Simpson EL. Eczema prevalence in the United States: data from the 2003 National Survey of Children's Health. J Invest Dermatol. 2011;131(1):67-73. doi: 10.1038/jid.2010.251. [PubMed: 20739951].

4. European Academy of Allergy and Clinical Immunology . Global Atlas of Allergy. Cezmi AA, Ioana A, editors. Switzerland: EAACI; 2014.

5. Olesen AB, Bang K, Juul S, Thestrup-Pedersen K. Stable incidence of atopic dermatitis among children in Denmark during the 1990s. Acta Derm Venereol. 2005;85(3):244-7. doi: 10.1080/00015550510026343. [PubMed: 16040411].

6. Boguniewicz M, Leung DY. Recent insights into atopic dermatitis and implications for management of infectious complications.J Allergy Clin Immunol. 2010;125(1):4-13. doi: 10.1016/j.jaci.2009.11.027. [PubMed: 20109729] quiz 14-5.

7. David TJ, Longson M. Herpes simplex infections in atopic eczema. Arch Dis Child. 1985;60(4):338-43. [PubMed: 4004311].

8. Tay YK, Khoo BP, Goh CL. The epidemiology of atopic dermatitis at a tertiary referral skin center in Singapore. Asian Pac J Allergy Immunol. 1999;17(3):137-41. [PubMed: 10697251].

9. Leung DY. Why is eczema herpeticum unexpectedly rare?. Antiviral Res. 2013;98(2):153-7. doi: 10.1016/j.antiviral.2013.02.010. [PubMed: 23439082].

10. Novelli VM, Atherton DJ, Marshall WC. Eczema herpeticum. Clinical and laboratory features. Clin Pediatr(Phila). 1988;27(5):231-3. [PubMed: 2835199].

11. Wollenberg A. Eczema herpeticum. Chem Immunol Allergy. 2012;96:8995. doi: 10.1159/000331892. [PubMed: 22433376].

12. Bork K, Brauninger $\mathrm{W}$. Increasing incidence of eczema herpeticum: analysis of seventy-five cases. J Am Acad Dermatol. 1988;19(6):1024-9. [PubMed: 3204177].

13. Korting GW, Krautheim H, Wieland W. [Eczema herpeticatum]. Med Welt. 1983;34(21):611-3. [PubMed: 6192310].

14. Hanifin JM. Diagnostic features of atopic dermatitis. Acta derm venereol (Stockh). 1980;92:44-7.

15. Oranje AP, Glazenburg EJ, Wolkerstorfer A, de Waard-van der Spek FB. Practical issues on interpretation of scoring atopic dermatitis: the SCORAD index, objective SCORAD and the three-item severity score. Br J Dermatol. 2007;157(4):645-8. doi: 10.1111/j.1365-2133.2007.08112.x. [PubMed: 17714568].
16. Bischoff-Ferrari HA, Giovannucci E, Willett WC, Dietrich T, DawsonHughes B. Estimation of optimal serum concentrations of 25hydroxyvitamin D for multiple health outcomes. Am J Clin Nutr. 2006;84(1):18-28. [PubMed: 16825677].

17. Wang TT, Nestel FP, Bourdeau V, Nagai Y, Wang Q, Liao J, et al. Cutting edge: 1,25-dihydroxyvitamin D3 is a direct inducer of antimicrobial peptide gene expression. J Immunol. 2004;173(5):2909-12. [PubMed: 15322146].

18. Gombart AF, Borregaard N, Koeffler HP. Human cathelicidin an timicrobial peptide (CAMP) gene is a direct target of the vitamin $\mathrm{D}$ receptor and is strongly up-regulated in myeloid cells by 1,25 dihydroxyvitamin D3. FASEB J. 2005;19(9):1067-77. doi: 10.1096/fj.043284com. [PubMed: 15985530].

19. Roider E, Ruzicka T, Schauber J. Vitamin d, the cutaneous barrier, antimicrobial peptides and allergies: is there a link?. Allergy Asthma Immunol Res. 2013;5(3):119-28. doi: 10.4168/aair.2013.5.3.119. [PubMed: 23638309].

20. Mutgi K, Koo J. Update on the role of systemic vitamin D in atopic dermatitis. Pediatr Dermatol. 2013;30(3):303-7. doi:10.1111/j.15251470.2012.01850.x. [PubMed: 22957498].

21. El Taieb MA, Fayed HM, Aly SS, Ibrahim AK. Assessment of serum 25-hydroxyvitamin d levels in children with atopic dermatitis: correlation with SCORAD index. Dermatitis. 2013;24(6):296-301. doi: 10.1097/DER.0000000000000010. [PubMed: 24201460].

22. Peroni DG, Piacentini GL, Cametti E, Chinellato I, Boner AL. Correlation between serum 25-hydroxyvitamin D levels and severity of atopic dermatitis in children. Br J Dermatol. 2011;164(5):1078-82. doi: 10.1111/j.1365-2133.2010.10147.x. [PubMed: 21087229].

23. Kim SM, Jang GC, Kim YJ, Cho NJ. Two Cases of Widespread Eczema Herpeticum with Low Serum Vitamin D Levels. Korean J Dermatol. 2013;51(11):893-7.

24. Wollenberg A, Zoch C, Wetzel S, Plewig G, Przybilla B. Predisposing factors and clinical features of eczema herpeticum: a retrospective analysis of 100 cases. J Am Acad Dermatol. 2003;49(2):198-205.

25. Schultz Larsen F, Hanifin JM. Secular change in the occurrence of atopic dermatitis. Acta Derm Venereol Suppl (Stockh). 1992;176:7-12. [PubMed: 1476042].

26. Bin L, Kim BE, Brauweiler A, Goleva E, Streib J, Ji Y, et al. Staphylococcus aureus alpha-toxin modulates skin host response to viral infection. J Allergy Clin Immunol. 2012;130(3):683-691 e2. doi: 10.1016/j.jaci.2012.06.019. [PubMed: 22840852].

27. Broccardo CJ, Mahaffey S, Schwarz J, Wruck L, David G, Schlievert PM, et al. Comparative proteomic profiling of patients with atopic dermatitis based on history of eczema herpeticum infection and Staphylococcus aureus colonization.J Allergy Clin Immunol. 2011;127(1):186-93. doi 10.1016/j.jaci.2010.10.033. [PubMed: 21211653] 193 e1-11.

28. Ong PY. Recurrent MRSA skin infections in atopic dermatitis. J Allergy Clin Immunol Pract. 2014;2(4):396-9. doi: 10.1016/j.jaip.2014.04.007. [PubMed: 25017526].

29. Jagadeesan S, Kurien G, Divakaran MV, Sadanandan SM, Sobhanakumari K, Sarin A. Methicillin-resistant Staphylococcus aureus colonization and disease severity in atopic dermatitis: a cross-sectional study from South India. Indian J Dermatol Venereol Leprol. 2014;80(3):229-34. doi: 10.4103/0378-6323.132250. [PubMed: 24823400].

30. Beck LA, Boguniewicz M, Hata T, Schneider LC, Hanifin J, Gallo R, et al. Phenotype of atopic dermatitis subjects with a history of eczema herpeticum. J Allergy Clin Immunol. 2009;124(2):260-9. doi: 10.1016/j.jaci.2009.05.020. [PubMed: 19541356] 269 e1-7.

31. Frisch S, Siegfried EC. The clinical spectrum and therapeutic challenge of eczema herpeticum. Pediatr Dermatol. 2011;28(1):46-52. doi 10.1111/j.1525-1470.2010.01356.x. [PubMed: 21261703]. 